\title{
A Study of Configuration of the Posterior Bifurcation of the Posterior Communicating Artery in the Circle of Willis
}

\author{
Dr. Saniya Harish Lade ${ }^{1}$, Dr. Sonal Anand Talokar ${ }^{2}$ \\ ${ }^{1}$ IGGMC, Nagpur \\ ${ }^{2}$ Assistant Professor (Anatomy), IGGMC, Nagpur
}

\begin{abstract}
Thomas Willis in 1962 described the anatomy of cerebral vessels and clearly recognized its functional significance. Considerable variation exist in circle of will is which are already studied and will be studied in this research also. This being important to neurosurgeons as variation may profound clinical implications. 70 adult brains were studied out of which 53 are males and 17 are females. Hypoplasia of posterior cerebral artery and posterior communicating artery are observed. Frequency of adult configuration is higher i.e $62.85 \% .10 \%$ showed foetal configuration while $12.85 \%$ of circles show transitional configuration in present study.
\end{abstract}

Keywords: Circle of willis, Anterior cerebral artery, Anterior communicating artery, Posterior cerebral artery, Internal carotid artery, Posterior communicating artery.

\section{Introduction}

Thomas Willis is considered one of the greatest neuroanatomists of all time. His name is associated with the circle of Willis, an anastomotic circle at the base of the brain. ${ }^{(1)}$ Circle of Willis also known as Willis Polygon is a circle of arteries that supply blood to the brain. It comprises of anterior cerebral artery, anterior communicating artery,posterior cerebral artery, internal carotid artery and posterior communicating artery. It is an anastomosis of basilar system and internal carotid system lying in the interpeduncular cistern. ${ }^{(2)}$

Most of the anatomical variations have been reported on the posterior cerebral and posterior communication arteries. ${ }^{(3)} \mathrm{A}$ higher percentage of abnormality has been reported in the mentally ill and in patients with cerebrovascular catastrophy, knowledge of which may also be of use to the surgeon in assessing the feasibility of shunt operations and in the choice of patients. ${ }^{(4)}$

In adults three configurations of the posterior bifurcation of the posterior communicating artery can be distinguished.

1) Adult -diameter of PCA $>$ diameter of PCOM

2) Transitional-diameter of $\mathrm{PCA}=$ diameter of $\mathrm{PCOM}$

3) Foetal -diameter of PCA $<$ diameter of $\mathrm{PCOM}^{(5)}$

\section{Aims and Objectives}

The study was carried out with the following aims and objectives:

1) To study the variations of vessels in posterior part of circle.

2) To find out any preponderance of variation in any particular vessel in this region.

3) To find out differences in males and females if any.

\section{Material and Method}

The present study was carried out in the Department of Anatomy from July 2009 to August 2011.It includes 70 human brains (53 males and 17 females) irrespective of the cause of death. Brains were obtained from Forensic department of IGGMC, Nagpur and from the cadavers in the dissection hall of our college.

Steps in studying the circle of willis:

1) Skull bones were carefully cut with hammer and chisel. Vault was removed and brain was taken out carefully after cutting the dura folds.

2) The removed brains were dipped in water and then washed under running water for 15 mins and now placed inverted over a clean surface to expose the base of brain; the water was soaked with tissue paper.

3) The circle of willis was observed at the base of brain Measurements of arteries forming the cicle of willis were taken with vernier calipers graduated to measure upto $0.5 \mathrm{~mm}$, at two different points and values were noted down on a preformed data sheet.

4) Finally, photographs were taken with digital cameras.In order to avoid errors due to different angles of view,images were taken almost perpendicular to the plane of the circles

\section{Results}

Results will be discussed under the following heading:

1) Posterior cerebral artery

2) Posterior communicating artery

3) Various configurations of posterior cerebral artery and posterior communicating artery. 


\section{International Journal of Science and Research (IJSR)}

ISSN (Online): 2319-7064

Index Copernicus Value (2013): 6.14 | Impact Factor (2014): 5.611

\section{Posterior Cerebral Artery:}

Table 1: Frequency distribution of PCA in right and left side of circle

\begin{tabular}{|c|c|c|c|c|c|c|c|c|c|c|}
\hline \multirow[t]{2}{*}{ NAME } & \multirow[t]{2}{*}{ Frq. } & \multicolumn{3}{|c|}{ (above 1mm diameter) } & \multicolumn{3}{|c|}{$\begin{array}{c}\text { H } \\
\text { (below 1mm diameter ) }\end{array}$} & \multicolumn{3}{|c|}{ Ab } \\
\hline & & $T=70$ & $M=53$ & $F=17$ & $T=70$ & $M=53$ & $F=17$ & $T=70$ & $M=53$ & $F=17$ \\
\hline PCA & R-NO. & 48 & 39 & 9 & 21 & 14 & 7 & 0 & 0 & 0 \\
\hline & $\%$ & 68.57 & 73.58 & 52.94 & 30 & 26.41 & 41.11 & 0 & 0 & 0 \\
\hline & L-NO & 45 & 37 & 8 & 25 & 16 & 9 & 0 & 0 & 0 \\
\hline & $\%$ & 64.28 & 69.81 & 47.05 & 35.71 & 94.11 & 52.94 & 0 & 0 & 0 \\
\hline
\end{tabular}

$68.57 \%$ arteries are measuring more than $1 \mathrm{~mm}$ and so considered normal on right side. While $64.28 \%$ left sided arteries is normal. Frequency of hypoplasia of vessel is $30 \%$ on right side and $35.71 \%$ on left side overall. In males, frequency of hypoplasia is significantly more on left side than on right side. In females it is almost equal.

\section{Posterior Communicating Artery:}

This is the artery which shows maximum variation according to literature.

Table 2: Frequency distribution of PCOM in right and left side

\begin{tabular}{|c|c|c|c|c|c|c|c|c|c|c|}
\hline \multirow{2}{*}{ NAME } & \multirow{2}{*}{ Frq. } & \multicolumn{3}{|c|}{$\begin{array}{c}\text { N } \\
\text { (above 0.5 mm) }\end{array}$} & \multicolumn{3}{c|}{$\begin{array}{c}\text { H } \\
\text { (below 0.5 mm) }\end{array}$} & \multicolumn{3}{c|}{ Ab } \\
\cline { 3 - 12 } & & T=70 & M=53 & F=17 & T=70 & M=53 & F=17 & T=70 & M=53 & F=17 \\
\cline { 3 - 12 } & R-NO. & 42 & 30 & 12 & 28 & 23 & 5 & 0 & 0 & 0 \\
\hline PCOM & \% & 60 & 56.60 & 70.58 & 40 & 43.39 & 29.41 & 0 & 0 & 0 \\
\hline & L-NO & 43 & 33 & 10 & 27 & 20 & 7 & 0 & 0 & 0 \\
\hline & \% & 61.42 & 62.26 & 58.82 & 38.57 & 37.73 & 41.17 & 0 & 0 & 0 \\
\hline
\end{tabular}

Arteries are measuring normal in $60 \%$ subjects on right side and $61.42 \%$ on left side. Absence of vessel is not seen.Frequency of hypoplasia is slightly more on right side(40\%) than left(38.57)

\section{Configurations:}

Distribution included bilateral or unilateral presence of configurations. In this study following observations are seen.

Table 3: Frequency distribution of configuration of PCA and PCOM in all the circles

\begin{tabular}{|c|c|c|c|c|c|c|}
\hline Configuration & $M$ & $\%$ & $F$ & $\%$ & TOTAL & $\%$ \\
\hline a)ADULTS B/L & 36 & 67.92 & 8 & 47.05 & 44 & 62.85 \\
\hline $\mathbf{R}$ & 3 & 5.66 & 1 & 5.88 & 4 & 5.71 \\
\hline $\mathbf{L}$ & 3 & 5.66 & 0 & 0 & 3 & 4.28 \\
\hline TOTAL & 42 & 79.24 & 9 & 52.94 & 51 & 72.85 \\
\hline b)FOETAL B/L & 6 & 11.32 & 1 & 5.88 & 7 & 10 \\
\hline $\mathbf{R}$ & 3 & 5.66 & 1 & 5.88 & 4 & 5.71 \\
\hline $\mathbf{L}$ & 4 & 7.54 & 1 & 5.88 & 5 & 7.14 \\
\hline TOTAL & 13 & 24.52 & 3 & 17.64 & 16 & 22.85 \\
\hline c)TRANSITIONAL B/L & 4 & 7.54 & 5 & 29.41 & 9 & 12.85 \\
\hline $\mathbf{R}$ & 3 & 5.66 & 0 & 0 & 3 & 4.28 \\
\hline $\mathbf{L}$ & 3 & 5.66 & 1 & 5.88 & 3 & 4.28 \\
\hline TOTAL & 9 & 16.98 & 6 & 35.29 & 15 & 21.42 \\
\hline
\end{tabular}

Frequency of adult configuration is higher in all the circles i.e $72.85 \% .10 \%$ showed foetal configuration while $21.42 \%$ of circles show transitional configuration. No major malefemale differences are noted in adult and foetal configuration. Frequency of transitional configuration is slightly more in females than in males.

\section{Discussion}

\section{Posterior Cerebral Artery}

In this study $68.57 \%$ arteries are measuring more than $1 \mathrm{~mm}$ and so considered normal on right side. While $64.28 \%$ left sided arteries are normal. Frequency of hypoplasia of vessel is $30 \%$ on right side and $35.71 \%$ on left side. These findings do not coincide with any previous study.

Study of Bertram C. A (1888) ${ }^{\mathbf{6}}$ shows $86.5 \%$ normal PCA. Prof.E.Fawcett (1905) ${ }^{7}$ noted in his study that the right posterior cerebral in 6 cases out of 700 arose from the corresponding internal carotid, the left posterior cerebral artery arose in 4 cases out of 700 from the corresponding internal carotid artery. Kamath $\mathbf{S}(\mathbf{1 9 8 1})^{4}$ found $11 \%$ posterior arteries with abnormal diameters. Kapoor $\mathbf{K}(\mathbf{2 0 0 8})^{\mathbf{8}}$ in her study revealed $73 \%$ normal arteries with $2.4 \%$ showing multiplication and $10.6 \%$ show hypoplasia. Abubakr H M(2009) ${ }^{9}$ in his study revealed $97.2 \%$ normal PCA on right side and $97.9 \%$ PCA on left side with $2.1 \%$ hypoplastic PCA.

\section{Posterior Communicating Artery}

This is the artery showing maximum variations according to literature. External diameters of $0.5 \mathrm{~mm}$ and less than $0.5 \mathrm{~mm}$ is considered hypoplastic in case of communicating arteries. Arteries are measuring normal in $60 \%$ subjects on right side and $61.42 \%$ on left side. Absence of any vessel is not seen. Frequency of hypoplasia is slightly more on right

\section{Volume 4 Issue 12, December 2015}




\section{International Journal of Science and Research (IJSR) \\ ISSN (Online): 2319-7064 \\ Index Copernicus Value (2013): 6.14 | Impact Factor (2014): 5.611}

side $(40 \%)$ than left (38.57\%) .Bertram C. A (1888) ${ }^{\mathbf{6}}$ found in twenty-eight cases the right was much larger than the left, in fifteen the left was larger than the right. In seven cases both vessels were extremely small.Absence of PCOM is about $4.5-6.5 \%$.Kamath $\mathbf{S}(\mathbf{1 9 8 1})^{4}$ observed hypoplasia in $10 \%$ arteries. .

\section{Configurations:}

Frequency of adult configuration is higher in all the circles i.e $72.85 \%$. $10 \%$ showed foetal configuration while $21.42 \%$ of circles show transitional configuration in present study. Bhattacharji S (1967) ${ }^{\mathbf{1 0}}$ observed $18 \%$ circles with fetal configuration in healthy controls while $29 \%$ circles in patients with cerebral infarction.

Present study result coincides with the results of Kamath $\mathbf{S}(\mathbf{1 9 8 1})^{\mathbf{4}}$ as far as adult configuration which is $73.5 \%$ and $25 \%$ fetal configuration. Frequency of transitional configuration in present study $(21.42 \%)$ is far more than the findings of $(1.5 \%) \quad$ Kamath $\mathbf{S}(\mathbf{1 9 8 1})^{4}$ Gunter H (2005) ${ }^{\mathbf{1 1}}$ found a higher percentage of fetal configurations in older circles of Willis. Fetal configuration was found in $56 \%$.Sahni D (2007) ${ }^{12}$ noted foetal type configuration in 3 children and 20 adults. K.Ranil D. De Silva (2010) ${ }^{\mathbf{1 3}}$ revealed in his study that the blood supply to the occipital lobe mainly via the PCA and ICA was seen in 59\% and 34\% of fetal brains, respectively, transitional configuration is seen in $7.4 \%$.

\section{Conclusion}

The present study was carried out with an aim to evaluate the variations in arteries forming the circle of Willis. We thus concluded that:

1) Complete and symmetric Circle Of Willis is necessary for proper cerebral circulation

2) Frequency of transitional configuration is slightly more in females than in males.

3) Hypoplastic posterior communicating artery is one of the common finding in this study.

\section{References}

[1] Cagatay Ûstun Dr. Thomas WillisÕ Famous Eponym: The Circle of Willis;Turk J Med Sci 34 (2004) 271274.

[2] Satheesha Nayak,Somayaji S N,Saumya K V ;Variant arteries at the base of the brain; International Journal of Anatomical Variation[2008]60-61.

[3] Paul S And Mishra S;Variation of the anterior cerebral artery in human cadavers:A dissection study;Journal of Anatomical society India 53[1]15-16[2004]

[4] Sylvia Kamath;Observations on length and diameter of vessels forming the circle of willis; Journal of Anatomy(1981);133;3;419-423.

[5] K Ranil D De Silva,Rukmal Silva,W.S.L Gunasekera ,R W Jayesekera;Prevalence of typical circle of willis and variation in anterior communicating artery :A study of a Sri Lankan population;Annals of Indian Academy of Neurology; July-Sept 2009; vol.12;issue 3;157-161.

[6] Bertram C.A.Windle-On arteries forming the circle of willis;journal of anatomy and physiology;1888 Jan;22[pt.2];289-293.
[7] Professor E.Fawcett,Dr.J.V.Blachford; The circle of willis:An examination of 700 specimens; journal of anatomy and physiology; 1905; vol.XL ,pg.83.

[8] K.Kapoor,Balbir Singh And Late Inder Jit Dewan;Variation In The Configuration Of The Circle Of Willis.Anatomical sciences International[2008]03,96-106.

[9] Abubakr HM Alawad, Mustafa A Hussein , Mohamed A Hassan. Morphology and normal variations of the Cerebral Arterial Circle of Willis" in Khartoum Diagnostic Centre. Khartoum Medical Journal (2009) Vol. 02, No. 02, pp. $215-219$.

[10] S. K. Battacharji, E. C. Hutchinson And A. J. Mccall; The Circle Of Willis - The Incidence Of Developmental Abnormalities In Normal And Infarcted Brains.Brain 1967;90;747-758

[11]H. Gunter Seydel; The diameters of the cerebral arteries of the human fetus The Anatomical Record-Volume 150 Issue 1, Pages 79 - 88: 3 Feb 2005

[12]Daisy Sahani ,Inder Jit ,Vivek Lal;Variation and anamolies of the posterior communicating artery in northwest Indian brains.Vol.68,Issue 4,Pages 449-453 Oct.2007.

[13]K Ranil D De Silva,Rukmal Silva,W.S.L Gunasekera ,R W Jayesekera;Comparison of the configuration of the posterior bifurcation of the posterior communicating artery between fetal and adult brains:A study of a Sri Lankan population;Ann Indian Acad Neurol;2010;13;198-201. 